\title{
Production and Characterisation of Bio-Oil from Agricultural Residues
}

\section{Francis Mintah Dadzie ${ }^{1, a^{*}}$, John Frimpong Kyei-Mensah ${ }^{1, b}$, Michael Boakye ${ }^{1, c}$}

\author{
${ }^{1}$ Kwame Nkrumah University of Science and Technology, Kumasi, Ghana \\ akofimintahfm@yahoo.com*, bjkmfrimpong@gmail.com, cgundalf10uk@yahoo.com
}

Keywords: Production, characterisation, bio oil, agricultural waste

\begin{abstract}
Energy crisis have become a global issue. Africa is one of the great contributors of agricultural produce, however no efficient way is established to covert the agricultural residues to useful products. Therefore, this study was to ascertain the combining effect of the agricultural residues on the yield and quality of bio oil produced. Biomass from cassava peel, rice husk and corn stalk were obtained and prepared. The sulphur and fixed carbon contents of the biomass were less making them more environmentally friendly. Biomass (i.e. cassava peel, rice husk, and corn stalk) were mixed in different concentrations of $1: 1: 1,2: 1: 1,1: 2: 1$, and 1:1:2 respectively and subjected to fast pyrolysis using a fixed bed reactor. The biomass concentration which gave the highest yield of bio-oil was $2: 1: 1$ with a yield of $55.63 \%$. This yield was reached at a temperature of $525^{\circ} \mathrm{C}$. However, the physicochemical properties of the high yielding bio-oil fairly satisfied the ASTM D7544 standards. Further improvement on the bio-oil will enhance its usefulness as a suitable alternative to diesel.
\end{abstract}

\section{Introduction}

Global energy crisis surfaced since the 1970s due to the heightened demand which resulted in decreasing levels of petroleum resources in the producing countries. Historically, coal was the only source of fossil fuel until 1860s where crude oil became an alternative source. Subsequently, the consumption of natural gas began in the late 1880 - 1990s. In recent times, crude oil is the largest energy source, representing about 39 percent of fossil energy, followed by coal and natural gas at 33 and 28 percent respectively [1]. Currently, a considerable focus has be shifted to the development of a third generation fuel through the use of biomass as sources for the production of fuels. Biomass sources are considered as a logical alternative for fossil fuels due to its capability of maintaining the net atmospheric $\mathrm{CO}_{2}$ levels [2]. Fuel potential producing biomass include woods, agricultural residues, organic wastes, and aquatic plants [3-6]. The conversion of biomass to bio oil can be carried out by several processes with recourse to the type and features of biomass and the type and quantity of energy required. With the aim of producing liquid fuels such as bio oil, current conversion technologies include pyrolysis and hydrothermal liquefaction. Pyrolysis involves the application of heat to decompose organic compounds in the absence of oxygen. Hydrothermal liquefaction entails the use of high pressure and temperature to maintain water in either liquid or supercritical state [7]. Interestingly, the product of pyrolysis include bio-oil, char, and fuel gas whereas that of hydrothermal liquefaction include bio-oil, fuels and chemicals [8]. Therefore, these two processes produce the same primary product. However, pyrolysis is efficient with dry biomass whereas hydrothermal liquefaction is appropriate for wet biomass.

Africa is one of the great contributors of agricultural produce, however no efficient way is established to covert the agricultural residues to useful products. The continent is characterised with abundance of filth from accumulated wastes from agricultural produce. Therefore, the production of bio oil on this continent is possible due to the availability of biomass. However, Bio oil is cleaner environmental friendly since plant biomass emits insignificant amounts of $\mathrm{SO}_{\mathrm{x}}$ as compared to fossil fuels [9]. Contrarily, bio oil is deficient in areas such as high viscosity, high corrosiveness, instability, and low heating value. Several studies have been carried out on the use of agricultural waste such as cassava peels, rice husk, and corn stalk. But this study is focused on producing bio-oil from the combination of cassava peels, rice husk, and corn stalk. Therefore, this study was to ascertain the combining effect of the agricultural residues on the yield and quality of bio oil produced. 


\section{Methodology}

Biomass Preparation and Proximate Analysis

Cassava peels, rice husk, and corn stalk were collected from cassava starch factory, rice farm and maize farm respectively in Kumasi, Ghana. Subsequently, the biomass were washed to get rid of dirt and dried in an oven for $24 \mathrm{~h}$ at $110^{\circ} \mathrm{C}$ to reduce the moisture content [10] to less than $15 \%$. One Kilogram each of the dried cassava peels, rice husk and corn stalk were grinded separately using a Bauer Mill. The grinded particles were screened using an 80/100 mesh to obtain particle sizes of about $150-180 \mu \mathrm{m}$.

A Perkin-Elmer $2400 \mathrm{CHNS} / \mathrm{O}$ elemental-analyser was used to analyse the chemical (i.e. lignin, cellulose, hemi-cellulose) and elemental composition (i.e. carbon, hydrogen, nitrogen, sulphur, and oxygen) of the grinded biomass. Moreover, the proximate analysis (i.e. volatile matter, ash, and moisture) of the biomass (i.e. cassava peel, rice husk, and corn stalk) were carried out. The fixed carbon contents of the biomass were calculated by deducting the total percentage of volatile matter, ash, and moisture from $100 \%$.

\section{Conversion of Biomass to Bio-oil}

During the conversion of biomass to bio-oil, a thermochemical process was chosen since it is relatively simple, usually requiring only one reactor, thus having a low capital cost. However, this process is non-selective, producing a wide range of products including a large amount of char [11]. A fixed bed reactor was used in carrying out the pyrolysis of the biomass. Equal amounts of $100 \mathrm{~g}$ (i.e 1:1:1) of biomass of cassava peel, rice husk and corn stalk were put into the fixed bed reactor. In maintaining the inert condition, nitrogen at a flow rate $3 \mathrm{~L} / \mathrm{min}$ was introduced to the reactor. Subsequently, the reactor was preliminarily subjected to heat at $25^{\circ} \mathrm{C} / \mathrm{min}$ and later risen to the working temperature range $\left(400-600^{\circ} \mathrm{C}\right)$ with a shorter gas residence time $(\sim 2 \mathrm{~s})$. Rapidly, the reactor was cooled to room temperature to truncate further reactions. Gaseous and vaporized products were transferred through a condenser to convert condensable volatiles to liquid. The liquid was collected with a beaker while a cotton wool filter was used to collect low partial pressure hydrocarbons.

Procedure was repeated using varying amounts of biomass (i.e. cassava peels, rice husk and corn stalk) thus $2: 1: 1 ; 1: 2: 1$; and $1: 1: 2$ respectively and heated at the working temperature (400$600{ }^{\circ} \mathrm{C}$ ). Yield of bio-oil and bio-char were measured using an analytical balance.

The yield of bio-oil and bio char were determined using this formula:

$$
\text { Yield of bio-oil }=\left(\frac{\text { Mass of liquid }}{\text { Mass of biomass }}\right) \times 100 \% \text {, }
$$

and

$$
\text { Yield of bio-char }=\left(\frac{\text { Mass of solid }}{\text { Mass of biomass }}\right) \times 100 \% .
$$

\section{Characterisation of Bio-oil}

Both high and low yield bio-oil were further analysed to identify the physical and chemical properties of the bio-oil produced from the biomass. The physical and chemical properties were analysed by complying to the American Society for Testing and Material (ASTM) test methods: density (ASTM 4052), pH (ASTM E70), kinematic viscosity (ASTM D445), pyrolysis solids content (ASTM D7579), water content (ASTM E203), sulfur content (ASTM D4294), ash content (ASTM D482), pour point (ASTM D97), and flash point (ASTM D93). 


\section{Results and Discussions}

\section{Components of Biomass}

The chemical and elemental compositions of the biomass were ascertained and result is shown in Table 1. Moreover, a proximate analysis of the biomass was carried out and result is shown in Table 2.

Table 1. Chemical and Elemental Composition of Biomass

\begin{tabular}{lccc}
\hline Properties & Cassava peel & Rice husk & Corn stalk \\
\hline Chemical Composition (Wt \%) & & & \\
Lignin & 10.11 & 8.17 & 9.02 \\
Cellulose & 47.45 & 43.32 & 40.07 \\
Hemi-cellulose & 36.23 & 31.15 & 28.71 \\
Elemental Composition (Wt \%) & & & \\
Carbon (C) & 57.42 & 38.25 & 51.17 \\
Hydrogen (H) & 8.31 & 7.02 & 4.92 \\
Oxygen (O)* & 31.42 & 51.10 & 42.00 \\
Nitrogen (N) & 2.53 & 2.91 & 1.73 \\
Sulphur (S) & 0.32 & 0.72 & 0.18 \\
HHV (MJ/kg) & 21.7 & 19.25 & 12.37 \\
\hline
\end{tabular}

* Calculated by difference

Table 1 clearly shows that the various biomass had high amounts of cellulose; indicating that they contain much fibers which are essential substrate for bio-oil production. Generally, biomass contains 35\%-50\% cellulose and 20\%-35\% hemicellulose, and 10\%-30\% lignin [12]. 5-7 Cellulose and hemicellulose can be converted to sugar monomers by hydrolysis process, which can be further fermented to ethanol.

Cassava peel and corn stalk had high amounts of carbon with the exception of rice husk which had relatively low carbon content. However, the sulphur contents of the various biomass were approximately less than $1 \%$ which indicates that the bio-oils produced are free from environmental contaminants.

Table 2. Proximate Analysis of Biomass

\begin{tabular}{lccc}
\hline Properties & Cassava peel (\%) & Rice husk (\%) & Corn stalk (\%) \\
\hline Moisture & 1.6 & 2.45 & 3.12 \\
Ash & 2.7 & 7.12 & 5.73 \\
Volatile & 78.53 & 75.32 & 74.21 \\
Fixed carbon* & 17.17 & 15.11 & 16.94 \\
Total & 100 & 100 & 100 \\
\hline
\end{tabular}

*Calculated by difference

Table 2 expresses that the fixed carbon content for the biomass were below $20 \%$. This indicated that less solid combustible residue was retained subsequent to the heating and expel of the volatiles. Results were similar to that produced by Mullen et al. [12]. The ash contents were below 10\%, signifying lesser amounts of inorganic components in the biomass. 
Yield of Products from Pyrolysis

The bio-oil yield of the various biomass (thus cassava peel, rice husk, and corn stalk) concentrations (i.e $1: 1: 1,2: 1: 1,1: 2: 1$, and 1:1:2) respectively were ascertained. Fig. 1 shows the yields of bio-oil from the various biomass concentrations.

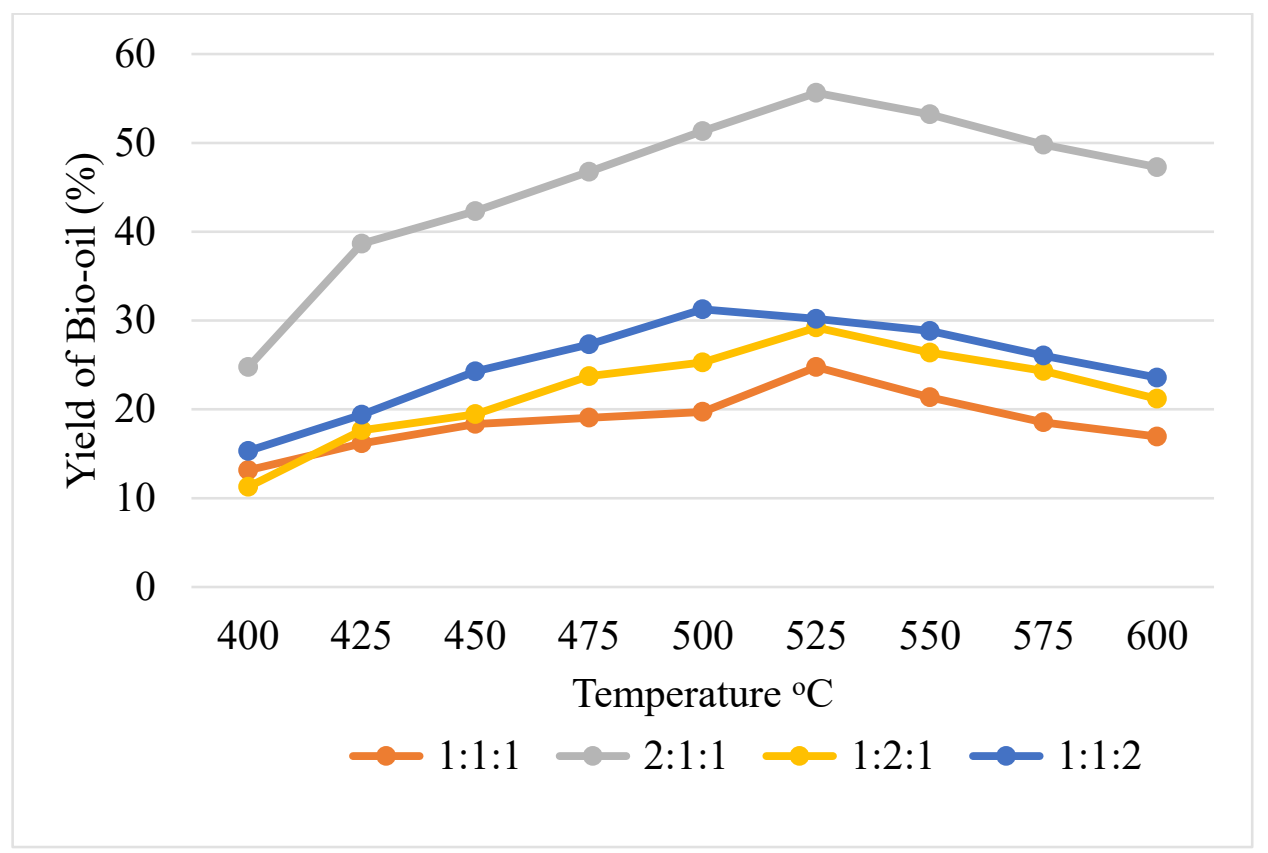

Figure 1. Yield of Bio-oil from Different Biomass Concentrations

The highest bio-oil yield of $55.63 \%$ was obtained at $525{ }^{\circ} \mathrm{C}$ for the substrate combination of $2: 1: 1$. However, the lowest oil yield of $11.27 \%$ was obtained at $400{ }^{\circ} \mathrm{C}$ for the substrate concentration of $1: 2: 1$. It became obvious that the temperature for maximum bio-oil yield for all various biomass concentrations was $525^{\circ} \mathrm{C}$. The bio-oil yield for all biomass across the various temperature range formed a parabolic shape. It can be deduced that extremely low $\left(400{ }^{\circ} \mathrm{C}\right)$ or high $\left(600^{\circ} \mathrm{C}\right)$ temperature will result in lower yields of bio-oil produced. A previous study conducted by $\mathrm{Ki}$ et al. [10] on biooil production from cassava peel showed similar bio-oil yield of $51.2 \%$ at $525{ }^{\circ} \mathrm{C}$, however a slow pyrolysis was used. Thermal degradation of hemicellulose and cellulose took place within the temperatures of 200 and $350{ }^{\circ} \mathrm{C}$ whereas lignin was decomposed at higher temperatures, usually within 280 and $500{ }^{\circ} \mathrm{C}$ [14].

\section{Characterisation of Bio-oil}

The overall bio-oil high yielding biomass concentration was $2: 1: 1$ while the overall low yielding biomass concentration. Table 3 shows the characteristics of the bio-oils produced.

Table 3. Physicochemical Properties of Bio-oil Produced

\begin{tabular}{lcc}
\hline Properties & $\mathbf{2 : 1 : 1}$ & $\mathbf{1 : 1 : 1}$ \\
\hline Density $\left(\mathrm{kg} / \mathrm{dm}^{3}\right)$ at $20{ }^{\circ} \mathrm{C}$ & 2.15 & 3.74 \\
$\mathrm{pH}$ & 5.92 & 4.17 \\
Water content $(\% \mathrm{wt})$ & 19.45 & 21.49 \\
Kinematic viscosity at $40{ }^{\circ} \mathrm{C}$ & 10.21 & 29.35 \\
Pyrolysis solids content & 0.39 & 1.31 \\
Sulfur content $(\% \mathrm{wt})$ & 0.12 & 0.79 \\
Ash content $(\% \mathrm{wt})$ & 0.21 & 0.45 \\
Flash point $\left({ }^{\circ} \mathrm{C}\right)$ & 76 & 65 \\
Pour point $\left({ }^{\circ} \mathrm{C}\right)$ & 4 & 2 \\
\hline
\end{tabular}


According to Volli and Singh [15], physicochemical properties such as viscosity, density, and flash point of bio-oil are essential characteristics for combustion purpose in boiler, furnace, gas turbines, and engines. The flash point of high yielding bio-oil was 1.69-fold higher than that of ASTM prerequisite $\left(76{ }^{\circ} \mathrm{C}\right.$ vs. $\left.45^{\circ} \mathrm{C}\right)$, signifying harmless handling and storage of the bio-oil in a thermostable environment. However, the direct use of the high yielding bio-oil for combustion purpose in the conventional diesel engines is fairly recommended since it contains less contaminants with high viscosity of ca. $10.21 \mathrm{cSt}$ than commercial diesel fuels of ca. 1.3-5.5 cSt (ASTM D975). With further purifications, the bio-oil will be free from contaminants, making it more useful and safer for vehicular consumption. Contrarily, low yielding bio-oil is highly not recommended due to the high viscosity of 29.35. High viscosity is known to influence poor atomization and an incomplete combustion of the fuel as well as the formation of excessive carbon deposits on the injection nozzles and the combustion chamber [15].

Nevertheless, the sulphur content of the bio-oils were $<1 \%$; indicating that the bio-oils produced were environmentally friendly. The relatively high amount of water in the bio-oils have the possibility of increasing the oxygen content of the bio-oils. This has the capacity of affecting the chemical and thermal stability, corrosivity, and immiscibility with hydrocarbon fuels. Therefore, several methods such as catalytic hydrotreatment can be adopted to reduce the oxygen content [16], supercritical water treatment (SCW) to raise the heating value [17], or esterification-distillation for eliminating large amount of water from the bio-oil [18].

\section{Conclusion}

The biomass concentration which gave the highest yield of bio-oil was 2:1:1 with a yield of $55.63 \%$. This yield was reached at a temperature of $525{ }^{\circ} \mathrm{C}$. Contrarily, the biomass concentration with the lowest yield of bio-oil was 1:1:1 with a yield of $11.27 \%$ at $400{ }^{\circ} \mathrm{C}$. However, the physicochemical properties of the high yielding bio-oil fairly satisfied the ASTM D7544 standards. But further improvement on the bio-oil will enhance its usefulness as a suitable alternative to diesel.

\section{Conflict of Interest}

The Authors declare that there is no conflict of interest.

\section{References}

[1] H. Ritchie, M. Roser, Fossil Fuels - Our world in Data. Available: https://ourworldindata.org/fossil-fuels.

[2] A. Demirbas, Current technologies for thermo-conversion of biomass into fuels and chemicals, Energy Sources. 26 (2004) 715-730.

[3] T. Minowa et al., Oil production from garbage by thermochemical liquefaction, Biomass and Bioenergy. 8(2) 1995 117-120.

[4] A. Demirbas, M. Balat, K. Bozbas, Direct and catalytic liquefaction of wood species in aqueous solution, Energy Sources, Part A. 27(3) (2005) 271-277.

[5] S. Xiu et al., Hydrothermal pyrolysis of swine manure to bio-oil: Effects of operating parameters on products yield and characterization of bio-oil, Journal of Analytical and Applied Pyrolysis. 88(1) (2010) 73-79.

[6] S. Xiu et al., Oil production from duckweed by thermochemical liquefaction, Energy Sources, Part A. 32 (2010) 1293-1300.

[7] A.B. Ross et al., Hydrothermal processing of microalgae using alkali and organic acids, Fuel. 89(9) (2010) 2234-2243. 
[8] F.M. Demirbas, Bio refineries for bio fuel upgrading: A critical review, Appl. Energy. 86 (2009) S151-S161.

[9] S. Xiu, A. Shahbazi, Bio-oil production and upgrading research: A review, Renewal and Sustainable Energy Reviews. 16 (2012) 4406-4414.

[10] L.O. Ki et al., Bio-oil from Cassava peel: A potential renewable energy source, Bioresource Technology. 145 (2013) 157-161

[11] G.W. Huber, J.A. Dumesic, An overview of aqueous-phase catalytic processes for production of hydrogen and alkanes in a biorefinery, Catalysis Today. 111(1-2) (2006) 119-132.

[12] R. Juneja, N. Abi, C. Ibaird, Review of biomass pyrolysis oil properties and upgrading research, Energy Conversion \& Management. 48 (2011) 87-92.

[13] A.C. Mullen et al., Bio-oil and bio-char production from corn cobs and stover by fast pyrolysis, Biomass and Bioenergy. 34(1) (2010) 67-74.

[14] Y.K. Park et al., Wild reed of Suncheon Bay: potential bio-energy source, Renewable Energy. 42 (2012) 168-172.

[15] V. Volli, R.K. Singh, Production of bio-oil from de-oiled cakes by thermal pyrolysis, Fuel. 96 (2012) 579-585.

[16] D.C. Elliott, G.G. Neuenschwander, Liquid fuels by low-severity hydrotreating of biocrude, in: A.V. Bridgwater, D.G.B. Boocock (Eds.), Developments in Thermochemical Biomass Conversion, vol. 1, Blackie Academic \& Professional, London, 1996, pp. 611-621.

[17] P. Duan, P.E. Savage, Upgrading of crude algal bio-oil in supercritical water, Bioresour. Technol. 102 (2011) 1899-1906.

[18] X. Junming et al., Bio-oil upgrading by means of ethyl ester production in reactive distillation to remove water and to improve storage and fuel characteristics, Biomass Bioenergy. 32 (2008) 1056-1061. 